\title{
A disciplina de libras como espaço de reflexões críticas e decoloniais na formação de professores
}

Ana Luisa Borba Gediel ${ }^{1}$

Carolina Macedo Lopes ${ }^{2}$

Victor Luiz Alves Mourão ${ }^{3}$

Resumo: Este trabalho tem como objetivo refletir sobre as implicações da disciplina de Libras na Formação de Professores, a partir das percepções de licenciandos de diferentes áreas do conhecimento. Em uma análise construída no campo da Linguística Aplicada e permeada pela discussão que envolve as políticas linguísticas e as noções de decolonialidade, discutimos a complexidade do desenvolvimento de uma disciplina a partir de múltiplas perspectivas. São pontuados os aspectos de padronização, reconhecimento, status linguístico e a igualdade de direitos dos grupos minoritários em usar sua primeira língua. A partir desse panorama, descrevemos a metodologia que proporcionou a realização da pesquisa. Em seguida discutimos o papel da disciplina de Libras para a construção de conhecimentos críticos tendo em vista sua organização em termos de conteúdos e objetivos, os quais envolvem a apreensão da Libras como primeira e como segunda língua, a interpretação de aspectos referentes à formação de professores voltada para a diversidade e inclusão e a

1 Professora do Departamento de Letras, Universidade Federal de Viçosa, Doutora em Antropologia Social (UFRGS), atuação na área de Libras e no Programa de Pós Graduação em Letras, na linha de pesquisa em Linguística Aplicada: formação de professores e ensino e aprendizagem de línguas. E-mail: ana.gediel@ufv.br

2 Licenciada em História pela Universidade Federal de Viçosa. Atuação como professora de Libras como segunda língua no Curso de Extensão em Libras - CELIB, Universidade Federal de Viçosa. E-mail: carolina.macedo@ufv.br

3 Professor, Universidade Federal de Viçosa, Doutor em Sociologia pelo Instituto de Estudos Sociais e Políticos (IESP/UERJ). Atuação no Departamento de Ciências Sociais, na área de Sociologia. E-mail: vmourao@ufv.br

Gláuks: Revista de Letras e Artes-jan/jun. 2020 - Vol. 20, $N^{o} 1$ 
relação do ensino da língua aliado a práticas pedagógicas. Para finalizar, concluímos que a disciplina tem um papel crítico reflexivo na formação dos futuros professores, envolvendo a construção de um olhar frente à língua e seu uso social.

Palavras-chave: Disciplina de Libras; formação de professores; decolonialidade; políticas linguísticas; ensino de línguas.

\section{Introdução}

Este trabalho surgiu a partir da problemática da educação de Surdos no cenário Brasileiro ${ }^{4}$. No país, o final do século XX e início do século XXI caracterizam-se por um conjunto de mudanças no contexto de ensino das pessoas Surdas (VIEIRA; MOLINA, 2018). Até 1996, o sistema educacional brasileiro para esse grupo de pessoas era restrito ao âmbito da educação especial. Após a Lei de Diretrizes e Bases Nacionais - LDBEN -, nº 9.394/96, tivemos um primeiro passo para a inserção do público da educação especial na rede regular de ensino (BRASIL, 1996). Até então, essa modalidade educacional estava subdividida em segmentos filantrópicos, classes especiais em escolas regulares de ensino e escolas especiais para Surdos, como na época eram popularmente conhecidas as atuais escolas bilíngues para educação de Surdos (FONTE, 2005).

4 Realizamos um breve panorama sobre o processo da entrada educacional dos Surdos na rede regular de ensino, para descrever nosso posicionamento favorável a educação bilíngue e o entendimento da necessidade de adequações na educação inclusiva.

Gláuks: Revista de Letras e Artes-jan/jun. 2020 - Vol. 20, $N^{o} 1$ 
Durante esse mesmo período, foi possível observar também as lutas das pessoas Surdas ${ }^{5}$ organizadas politicamente em comunidades, como se autodenominam, e com o apoio científico desenvolveram pesquisas e manifestações acadêmicas refletindo sobre os direitos de acesso à educação, à saúde e outras necessidades básicas. Essas lutas provocaram uma mudança paradigmática no modo como essas pessoas são tratadas socialmente. Essa mudança envolveria o reconhecimento da educação como uma instância fundamental de câmbio na forma de olhar as pessoas Surdas, para entendê-las como um grupo cultural específico, com demandas identitárias e linguísticas, que ultrapassam a visão estabelecida da deficiência sensorial para uma visão cultural e identitária de sua formação ${ }^{6}$. Nessa conjectura estão imersas as discussões voltadas para a noção de Bilinguismo e de educação bilíngue (SKLIAR, 1998).

Ao mesmo tempo, estudos sobre a língua de sinais são realizados para uma apresentação formal de aspectos linguísticos da Língua de Sinais Brasileira - Libras (QUADROS; KARNOPP, 2004), para nortear cientificamente a ideia de que os Surdos possuem uma língua própria, catalogando e pesquisando os aspectos gramaticais (BRITO, 1995; ALBRES, 2005). Esse histórico é fortalecido com a regulamentação da Libras. A Lei n ${ }^{\circ}$ 10.436/2002, destacase como um importante acontecimento, reconhecendo a Libras como uma Língua de estrutura gramatical e meio de comunicação/expressão natural das comunidades Surdas Brasileiras (BRASIL, 2002).

Nesse contexto, a educação regular apresenta a noção de educação inclusiva, decompondo as classes especiais e apresentando a alternativa de entrada dos alunos Surdos

5 A utilização da palavra surdo com s maiúsculo denota àquelas pessoas que politicamente referem-se à Libras como primeira língua e se consideram pertencentes à cultura Surda (PADDEN; HUMPHRIES, 2006).

6 Neste trabalho não enfatizaremos a discussão deficiência $x$ diferença. Ao nos referirmos ao termo "deficiência" retomamos as discussões que consideram as limitações sensoriais e cognitivas, tendo em vista o padrão da pessoa ouvinte como a normalidade auditiva. Já a noção da diferença é utilizada pelo próprios Surdos -, política e elaborada pelos Surdos, remetendo-se a uma identificação cultural especifica frente à sociedade majoritária e a legislação (GEDIEL, 2010).

Gláuks: Revista de Letras e Artes-jan/jun. 2020 - Vol. 20, $N^{o} 1$ 
em uma mesma sala de aula. A sala de recursos transforma-se em Atendimento Educacional Especializado (AEE), em contraturno às aulas (DAMÁZIO, 2007). As escolas bilíngues passam a ser vislumbradas como a educação almejada pelos Surdos e profissionais da educação (SILVA et al., 2018). Entretanto, há um número reduzido de escolas que estão concentradas em alguns estados. Desse modo, grande parte dos alunos continuava na rede regular de ensino sem acesso às escolas para Surdos. Houve, então, a necessidade de revisão das práticas e da noção imbuída na educação inclusiva referente às matrículas desses alunos. Schubert e Pereira (2019), evidenciam os desafios e limitações a serem enfrentados na formação dos professores levando em conta sua capacitação para uma educação bilíngue na denominada educação inclusiva, distanciando-se do risco de fortalecimento do colonialismo. Essa problemática leva em consideração o suporte à perspectiva da diferença linguística dos alunos Surdos, a qual já havia sido disposta na Lei de Libras. E referente à formação dos professores, o respeito aos aspectos culturais e linguísticos dos alunos Surdos foi instituído o Decreto $\mathrm{n}^{\circ} 5.626 / 2005$ (BRASIL, 2005).

O referido decreto regulamenta a Lei de Libras e delibera sobre a formação de professores, instrutores e intérpretes de Libras - Língua portuguesa, salvaguardando o direito à educação dos alunos Surdos, atuando para a disseminação e utilização da Libras e do português para introdução de surdos no sistema de ensino Brasileiro (BRASIL, 2005).

Observamos um contexto ideal, marcado por lutas e conquistas que foram travadas, Leis que surgiram e foram aplicadas. No entanto, temos um pano de fundo que não foi trabalhado, uma herança colonial, de entendimento das pessoas Surdas pela ótica da deficiência, sem o reconhecimento da língua e da alteração de práticas pedagógicas condizentes com sujeitos bilíngues/biculturais ${ }^{7}$. Desse modo, assim como Mignolo descreve, é preciso voltar-nos para

7 Nos amparamos em Kozlowski (1995), cujo objetivo na educação para a definição voltada para a educação bilingue/bicultural "é permitir aos indivíduos surdos um acesso completo a uma língua natural (a de sinais), que permite

Gláuks: Revista de Letras e Artes-jan/jun. 2020 - Vol. 20, $N^{o} 1$ 
ações decoloniais, que "focam na enunciação, se engajando na desobediência epistêmica e se desvinculando da matriz colonial para possibilitar opções decoloniais - uma visão da vida e da sociedade que requer sujeitos decoloniais, conhecimentos descoloniais e instituições descoloniais" (MIGNOLO, 2017, p.2).

A visão crítica de Schubert e Pereira (2019) sobre a formação de professores para uma educação bilíngue nos impulsiona a pesquisar e refletir sobre as propostas de inclusão, após as garantias estatais advindas basicamente por meio da implantação da legislação. Propomos, desse modo, apresentar uma pesquisa para a obtenção de um perfil dos professores em formação inicial, em uma IES no interior de Minas Gerais, levando em consideração que eles possam vir a atuar na educação inclusiva e ter alunos Surdos em sala de aula. Nossos questionamentos buscaram compreender quais os avanços ou possíveis transformações relativas à educação bilíngue/bicultural podemos observar em licenciandos que cursaram a disciplina de Libras.

Entendemos que a inserção dessa disciplina em universidades proporciona a abertura de um espaço para formação crítica. Por meio da pesquisa qualitativa, foi possível obter a perspectiva de discentes advindos de diferentes cursos de licenciatura e entender a respeito da construção de conhecimentos desenvolvidos na disciplina para atuar frente à educação inclusiva. Nesse sentido, este artigo insere-se no campo da Linguística Aplicada, envolvendo noções de decolonialidade e políticas linguísticas para refletir acerca da complexidade de enunciados coloniais que estes licenciandos carregam consigo e as possíveis transformações desse pensamento por meio das discussões geradas durante a disciplina de Libras.

uma aquisição normal da linguagem nesta primeira língua” (KOZLOWSKI,1995, p.154).

Gláuks: Revista de Letras e Artes-jan/jun. 2020 -Vol. 20, $N^{o} 1$ 


\section{A legitimação da Libras: demarcação de espaços em uma perspectiva decolonial}

A comunidade $\operatorname{Surda}^{8}$ brasileira, durante o final do século XX e meados do século XXI, foi gradativamente alcançando legitimidade e espaço em diversas esferas sociais, bem como o atendimento aos seus direitos para adequação às particularidades culturais $\mathrm{e}$ linguísticas, visando a busca por uma equidade. De acordo com Nora (2017)", o fortalecimento linguístico por meio de pesquisas, a criação de espaços voltados para educação de Surdos e, também, o desenvolvimento de discussões em torno da proposta do bilinguismo na educação desse público são frutos de um processo de elaboração de políticas linguísticas que possibilitou o reconhecimento da Libras.

Entendemos esse histórico de lutas por uma perspectiva decolonial, uma vez que ao buscar a inclusão e o reconhecimento do status linguístico da Libras, a comunidade Surda precisa romper com barreiras comunicacionais e sociais e modificar a percepção identitária da sociedade em relação ao próprio grupo. Assim como aponta Pardo (2019), há a necessidade de rompimento de paradigmas e de noções naturalizadas, buscando a superação de determinados padrões preestabelecidos hierarquicamente. $\mathrm{O}$ debate em pauta desse grupo minoritário afina-se com a definição de decolonialidade apresentada pelo autor, que:

(...) busca romper tais paradigmas cristalizados nas relações socioculturais, políticoeconômicas, étnico-raciais e de gênero/sexualidade. No meu entendimento, a fím de promover relações de poder mais igualitárias entre diferentes seres e saberes, a teoria decolonial procura identificar hierarquias invisíveis e desigualdades

8 O termo Comunidade Surda é êmico e abrange os grupos de pessoas Surdas que se reconhecem mutuamente enquanto tal e usam a Libras como primeira língua, participam de associações, elou grupos, elou encontros para discutir, entre outros aspectos, sobre questões políticas, sociais e educacionais.

Gláuks: Revista de Letras e Artes-jan/jun. 2020 - Vol. 20, $N^{o} 1$ 
naturalizadas, as quais tentam impor uma homogeneidade sobre a heterogeneidade humana (PARDO, 2019, p.210).

Nesse sentido, para refletir sobre decolonialidade é preciso compreender como as pessoas estão presentes na sociedade e quais fatores as colocam em determinada posição e condição para vivenciar os acontecimentos. Ainda, reconhecer que todos nós estamos inseridos em um cenário regido pelo pensamento colonial, que nos influencia e nos direciona socialmente. Conforme Mignolo (2014, tradução nossa), trata-se de uma estrutura que nos mantém e nos classifica enquanto seres com distinções variadas, como as linguísticas, de raça, entre outras. Essas distinções servem para oprimir e para justificar processos de dominação sobre grupos sociais. Tendo vista que esta estrutura se aplica a todos os espaços os quais ocupamos, ao refletir sobre o contexto de ensino, o autor argumenta que os educadores devem trabalhar de modo consciente com os alunos, auxiliando-os na identificação e no entendimento da influência colonial em sua vida.

O oferecimento da disciplina de Libras no ES implica em um importante passo para disseminação e prática do pensamento decolonial na formação dos futuros professores, uma vez que propõe uma perspectiva crítica de entendimento acerca da língua, gerando reflexão e empoderamento. Assim, para além das práticas de ensino e aprendizagem vinculadas diretamente aos conteúdos linguísticos, essa disciplina se coloca como um espaço de tomada de consciência das práticas coloniais que permeiam nosso cotidiano. A partir disso, estamos refletindo conscientemente sobre a língua e desenvolvendo políticas linguísticas. Como aponta Pardo (2019, p.219), "alguns caminhos para a decolonialidade no ensino de línguas no Brasil e para a construção do conhecimento corporificado passam necessariamente por um posicionamento crítico em relação aos objetivos do ensino do idioma".

Gláuks: Revista de Letras e Artes-jan/jun. 2020 -Vol. 20, $N^{o} 1$ 
Concebemos aspectos decoloniais em três circunstâncias: um, de forma mais abrangente, a partir do vigor do Decreto; dois, com o processo de implementação da disciplina no contexto de ensino; e, três, por meio das discussões em sala de aula, alterando em âmbito microssocial as noções culturais e linguísticas acerca dos sujeitos Surdos. Sobre a legislação, é preciso ter um olhar cauteloso. Segundo Pereira e Schubert (2019, p.173 - 174), a imprecisão e a abrangência da Lei de Libras (BRASIL, 2002) colocam fatores problemáticos que impõem impasses para a decolonialidade. As autoras descrevem que, apesar do reconhecimento da Libras como a língua dos Surdos, não existe uma garantia de que esse público e os agentes envolvidos nesse contexto, por exemplo os professores em formação continuada e os estudantes Surdos na rede regular de ensino, terão acesso à língua.

Pesquisas realizadas com o foco na disciplina de Libras no Ensino Superior indicam os desafios e avanços que envolvem o contexto dessa desde a implementação até o seu efetivo oferecimento (DE AQUINO SOUZA, 2017 - MARTINS, 2008 - LEMOS; CHAVES, 2012 XAVIER, 2018). Os estudos reconhecem, pela análise de documentos e entrevistas com cursistas, a importância da disciplina na formação de professores ao tratar de aspectos linguísticos, culturais e históricos dos Surdos.

Nesse quadro, mesmo com avanços na visibilidade e reconhecimento linguístico, ainda existem diversas crenças presentes na sociedade que reforçam uma ideia simplificada sobre os Surdos e a língua de sinais. De acordo com Lemos e Chaves (2012, p.2), “infelizmente, ainda é grande o desconhecimento, gerando, uma política de resistência, desvalorização e desrespeito ao estatuto linguístico da Libras". A investigação realizada por Martins (2008) apresenta os discursos dos estudantes que cursam as disciplinas de Libras, os quais estão marcados por mitos vinculados à língua. Segundo a autora, estas narrativas evidenciam diversos questionamentos e opiniões sobre a importância, a validade e a

Gláuks: Revista de Letras e Artes-jan/jun. 2020 - Vol. 20, $N^{o} 1$ 
relevância da disciplina, assim como o ceticismo e o desconhecimento voltado ao caráter linguístico dessa língua (MARTINS, 2008).

Nesse seguimento, em uma pesquisa com licenciandos que estavam cursando a disciplina de Libras, De Aquino Souza (2017) realizou aplicação de questionários em dois diferentes momentos da disciplina (em seu início e em seu término). A autora descreveu a mudança na percepção dos estudantes a respeito da Libras e dos Surdos, concluindo a importância da disciplina na formação dos licenciandos, uma vez que esta é um espaço que propicia reflexões e desconstruções do senso comum, fornecendo ao futuro professor uma base para lidar com alunos Surdos em sua prática docente.

Também se figura durante as aulas da disciplina a tentativa de desmistificação do prestígio naturalizado das línguas orais em relação às línguas de sinais. O caráter espontâneo de desenvolvimento linguístico da Libras, incluindo os aspectos icônicos e arbitrários na conformação gramatical exemplificam reflexões que podem ser tomadas como um processo que provoque uma percepção decolonial no ensino dessa língua. Severo (2013) descreve que as noções de prestígio das línguas são em uma primeira instância de natureza política, visto que as mesmas espelham hierarquias sociais e linguísticas a partir da representação de determinados grupos sociais em relação a outros. Essa discussão insere-se, também, no debate que envolve as políticas linguísticas. De acordo com Sousa e Soares (2014), a discussão das políticas linguísticas abarca o entendimento das noções de inclusão e de exclusão social, baseada naqueles que dominam ou não determinada língua.

Entendemos políticas linguísticas de forma ampla, ou seja, além da elaboração da legislação e de políticas regulamentadas institucionalmente, as políticas linguísticas também podem ser evidenciadas no sentido de propiciar espaços de discussões em relação à língua, indo ao encontro da definição apresentada por Kanavillil Rajagopalan, que as compreende

\section{Gláuks: Revista de Letras e Artes-jan/jun. 2020 -Vol. 20, $N^{o} 1$}


como "[...] a arte de conduzir a reflexões em torno de línguas específicas, com o intuito de conduzir ações concretas de interesses público relativo à(s) línguas(s) que importam para o povo de uma nação, de um estado ou ainda, instâncias transnacionais maiores”( 2013, p.21).

A opção do breve diálogo teórico entre as noções de decolonialidade e políticas linguísticas nos coloca em um posicionamento de análise e de defesa à continuidade da disciplina de Libras no âmbito do ES, considerando implicações para um desenvolvimento crítico nos espaços educacionais. Embora a disciplina ainda necessite de ajustes institucionais e pedagógicos em relação à sua padronização, vislumbramos vários benefícios, sendo eles: debates e reflexões envolvendo os aspectos gramaticais da língua de sinais, seu status linguístico, a desmistificação sobre as dificuldades cognitivas de aprendizagem dos Surdos. Estes são conhecimentos naturalizados e invisibilizados, remetendo à uma hierarquização de uma língua superestimada em relação à outra (MEGALE, 2018).

A partir da discussão de decolonialidade conseguimos apontar os processos coloniais, de exclusão/inclusão e barreiras sociais que nos orientam na reprodução de práticas opressoras e desiguais com relação aos Surdos. E tratando-se das políticas linguísticas, propomos um processo de agência frente à realidade atual, demonstrando também os aspectos coloniais existentes.

\section{Percurso metodológico}

Optamos pela perspectiva qualitativa porque compreendemos, conforme Minayo (2012), que esta pesquisa possui instrumentos e teorias que permitem vivenciar diferentes aspectos que acontecem entre as pessoas na sociedade. A investigação foi desenvolvida

Gláuks: Revista de Letras e Artes-jan/jun. 2020 - Vol. 20, $N^{o} 1$ 
usufruindo dos preceitos etnográficos, visto que utilizamos como instrumentos de pesquisa a observação participante, notas de campo, diário de campo e questionários (LAPLANTINE, 2003).

A fim de obter as percepções dos licenciandos acerca da disciplina de Libras, optamos pela aplicação de questionários ${ }^{9}$. Como menciona Gil (2008, p. 121), trata-se de um "conjunto de questões que são submetidas a pessoas com o propósito de obter informações sobre conhecimentos, crenças, sentimentos, valores, interesses, expectativas, aspirações, temores, comportamento presente ou passado". Desse modo, buscamos a contribuição da disciplina de Libras para professores em formação que irão atuar com alunos Surdos em ambientes multi/bilíngues.

O questionário foi aplicado em uma turma de uma disciplina de Libras da IES situadas no interior do estado de Minas Gerais. Foram elaboradas três questões, sendo uma fechada e duas abertas. A análise dos dados para este artigo centrou-se apenas nas questões abertas: 1) Quais conhecimentos você tinha a respeito da Libras e da educação de Surdos antes de se matricular na disciplina de Libras? 2) Em relação à didática do professor, como é o processo de ensino-aprendizagem? O questionário possuía ainda uma solicitação para que o estudante fizesse comentários e sugestões.

Participaram 21 estudantes de um total de 30 matriculados na turma. Esses alunos estavam vinculados a cursos de diferentes áreas do conhecimento (Educação Física, Geografia, Letras, Física, Ciências Sociais e Serviço Social) e se encontravam em períodos distintos, cursando entre o $4^{\circ}$ e o $9^{\circ}$ período de graduação, durante o ano letivo de 2019 . Antes

9 Os dados apresentados neste estudo pertencem a um projeto maior envolvendo as disciplinas de Libras de uma Instituição Federal de Ensino Superior na Zona da Mata Mineira. Os questionários foram distribuidos no último dia de aula de uma das disciplinas de Libras da instituição.

Gláuks: Revista de Letras e Artes-jan/jun. 2020 - Vol. 20, $N^{o} 1$ 
de receber os questionários, todos os colaboradores foram informados dos objetivos da pesquisa e do sigilo e anonimato das respostas dadas ${ }^{10}$.

Em sequência, realizamos a transcrição e a organização dos dados, a partir da criação de categorias analíticas (MINAYO, 1998). A autora descreve que a análise das categorias pode ser realizada a partir da divisão do conteúdo coletado por meio da aproximação de elementos similares e do distanciamento daqueles que remetem a outros sentidos. Desse modo, inicialmente foi realizado o mapeamento de todos os dados recolhidos e a classificação a partir das seguintes palavras-chave: mitos e crenças; conhecimentos sobre cultura e identidade surda; e conhecimentos linguísticos sobre a Libras e sua história. As três categorias analíticas surgiram através da decupagem dos dados e da revisão das respostas referentes às duas questões abertas.

\section{E como está o fazer pedagógico dos professores em formação? Um olhar acerca da contribuição crítica da disciplina de Libras}

Neste trabalho, analisamos as respostas dos licenciandos e identificamos uma mudança de pensamento após cursar a disciplina, sendo que a maioria descreveu não conhecer de forma prática a Libras e/ou a realidade dos Surdos antes de cursar os conteúdos nela ofertados. Observamos o desenvolvimento de uma consciência crítica em relação aos mitos e crenças sobre a Libras, noções culturais e identitárias das pessoas Surdas, assim como aspectos educacionais.

10 Os dados apresentados neste trabalho inserem-se em uma pesquisa maior, sua realização foi aprovada pelo comitê de ética em pesquisa - CEP. Optou-se pela utilização de pseudônimos para apresentar as respostas dos estudantes.

Gláuks: Revista de Letras e Artes-jan/jun. 2020 - Vol. 20, $N^{o} 1$ 
Inicialmente, alguns licenciandos descreveram que tinham apenas a consciência de que a Libras existia e/ou que era a usada pelos Surdos, mas sem ter o contato com pessoas Surdas ou com a língua, conforme ilustra o excerto: Conceição afirma que antes de cursar a disciplina se considerava "completamente leiga" e, posteriormente, teve "a compreensão de alguns "aspectos básicos da língua, creio que a disciplina também me mostrou que Libras não é uma língua de outro mundo e é possível aprendê-la (Conceição, Educação Física, $6^{\circ}$ período). Este excerto nos possibilitou duas análises: uma em relação aos mitos voltados para a Libras e, outra, sobre as crenças de ensino da língua.

De acordo com Gesser (2009), é necessário reafirmar a importância, a autenticidade linguística da Libras mesmo após décadas de estudos voltados para o reconhecimento da língua de sinais e de seu status linguístico. Segundo a autora, muitas pessoas ainda lidam com estranheza ao discutir tais temáticas e acabam por reproduzir mitos e crenças. Gesser (2009) afirma que esse debate carrega consigo um tom de repetição, mas ainda é desconhecido para muitos, indicando a necessidade de esclarecimentos contínuos. Acreditamos que os mitos são reforçados por um estigma colonial, de afirmações que denotam a língua de forma desvalorizada.

O conceito de crenças a partir de Barcelos (1995, p. 40) é definido como um “conhecimento intuitivo implícito (ou explícito) dos aprendizes constituído de crenças, mitos, pressupostos culturais e ideais sobre como aprender línguas". A autora demonstra a necessidade de averiguar a compatibilidade dos conhecimentos em relação à idade, nível social e econômico, além das noções anteriores do aprendiz referentes a outras línguas e seu contexto educacional (BARCELOS, 1995). Assim, quando Conceição remete-se ao fato de que a Libras é uma língua que pode ser apreendida, observamos a crença em relação à impossibilidade de aprender essa língua, a qual foi superada a partir do contato na disciplina.

\section{Gláuks: Revista de Letras e Artes-jan/jun. 2020 -Vol. 20, $N^{o} 1$}


Conforme Barcelos (2004), as pesquisas sobre crenças no âmbito da Linguística Aplicada devem abordar o processo reflexivo dos estudantes, levando em consideração suas vivências e as interpretações sobre elas. Ainda, a autora observa que o processo de ensino e aprendizagem de línguas é complexo, sendo necessário atentar para a forma como os estudantes lidam com as suas próprias crenças ao aprender uma língua.

Nesse sentido, Barcelos (2004) aponta para a criação de espaços para discutir acerca das crenças em sala de aula, já que essa prática é essencial no processo de formação dos futuros professores e também de seus alunos. A identificação e problematização das crenças que os cercam proporcionam o desenvolvimento de uma compreensão crítica sobre o ensino e seu fazer. Dandara identificou sua crença assim como a mudança de pensamento após cursar a disciplina de Libras: "eu achava que todo Surdo era mudo e não sabia nada sobre a língua de sinais" (Dandara, Educação física, $6^{\circ}$ período). Gesser (2009) desmistifica tal noção, ao mostrar que nem toda pessoa com surdez é muda, ao possuir o canal fonador intacto a pessoa - independentemente de ser Surda ou não -, se encontra apta a desenvolver a fala de forma oral. De acordo com a autora, essa ideia se justifica porque o conceito "fala" está vinculado a uma produção oral.

Além disso, os estudantes relataram sobre a importância da representatividade da Libras para a Comunidade Surda: "hoje já sei que a Libras além de ser uma língua para os Surdos/as [é a] forma de comunicação que eles se sentem pertencentes, é também uma cultura para eles e o meio onde estes se sentem mais à vontade em meio a sociedade" (Eliana, Geografia, $8^{\circ}$ período). A partir do posicionamento da licencianda nos remetemos ao entendimento da definição de cultura que é apresentada pela própria Lei de Libras, descrevendo que as pessoas Surdas são aquelas que interagem "com o mundo por meio de experiências visuais, manifestando sua cultura principalmente pelo uso da Libras" (BRASIL,

\section{Gláuks: Revista de Letras e Artes-jan/jun. 2020 -Vol. 20, $N^{o} 1$}


2002, art. $2^{\circ}$ ). Nessa conjectura, o pertencimento a um grupo que compartilha uma língua e que luta pela sua visibilidade, incluindo o próprio reconhecimento cultural, são fatores vinculados ao ensino e aprendizagem da língua de forma crítica, assim como percebemos no relato de Fernando:

Antes de me matricular na disciplina eu não havia[sic] nenhum conhecimento sobre o assunto, após cursá-la, percebi a importância do acesso à comunicação para com os surdos, tanto quanto a capacitação que devemos ter para garantir o acesso total e garantido há[sic] educação. Aprendi também sobre a cultura surda e que não há absolutamente nenhuma defasagem se comparado a pessoas ouvintes, apenas métodos diferentes de se comunicar (Fernando, Geografia $8^{\circ}$ período).

O acesso à comunicação descrito pode ser vinculado à discussão clássica dos estudos de Góes (1999), relativo às dimensões do papel da linguagem na educação de Surdos, em que o aprendizado da língua implica, de certa forma, no modo de atribuir significações ao mundo por intermédio da linguagem, dimensionando peculiaridades culturais. De acordo com Dizeu e Caporali (2005, p.590), “[...] por meio da língua passamos a compreender o mundo, constituindo nosso cognitivo e o subjetivo, criando pelas nossas experiências e concepções próprias, de tudo e todos que fazem parte de nosso meio".

Em relação à cultura, Duranti (1997) apresenta diversos panoramas, dentre eles, o vinculado às minorias e aos grupos marginalizados, os quais não são assimilados pela sociedade majoritária. A relação entre língua e cultura, de acordo com autor, advém do entendimento que a noção de cultura é concebida como um sistema de práticas que está relacionado com ações coletivas e participativas, incluindo os processos comunicativos. Duranti (1997) afirma que essa noção de cultura pode ser aplicada para o entendimento do uso da língua em situações de interação, em que as palavras tragam o efeito de estabelecer comunicação, trocas e reciprocidade. $\mathrm{O}$ autor justifica ainda que "falar uma língua significa

\section{Gláuks: Revista de Letras e Artes-jan/jun. 2020 -Vol. 20, $N^{o} 1$}


estar apto a participar em interações com uma palavra que é sempre maior que nós como indivíduos comunicadores e ainda maior que o que nós podemos ver e tocar em qualquer situação dada" (Duranti, 1997, p.46).

Desse modo, a língua é empoderadora, possui a característica humana de compartilhar mensagens que levam a uma série de atos, como o da possibilidade de aprender, expressar sentimentos e sistemas de crenças (GEDIEL, 2010). A escola, por meio da interação entre professores e alunos, oferece situações sociais para a construção das interações. Assim, ao entenderem a importância de comunicar com seu aluno Surdo, os professores em formação inicial demonstram ter noções sobre as especificidades culturais e linguísticas. Gilberto conta que após cursar a disciplina, percebeu "a importância do acesso à comunicação para com os surdos, tanto quanto a capacitação que devemos ter para garantir o acesso total à educação" (Gilberto, período não informado, Geografia).

A maioria dos alunos também demonstrou que a disciplina lhes proporcionou uma base para lidar com Surdos no contexto escolar, possibilitando-os conhecer novas estratégias de ensino. A discussão sobre inclusão x exclusão dos alunos Surdos em sala de aula foi explicitada por Ísis: “Agora tenho um ótimo referencial e uma boa base para que eu possa continuar desenvolvendo práticas inclusivas para todos" (Educação Física, $8^{\circ}$ período). A necessidade de pertencimento às aulas e o entendimento da identificação do professor ficou nítida quando Jade descreveu que "a Libras também me mostrou e me fez compreender que as crianças surdas podem sim ter aulas e que elas se sintam cada vez mais pertencentes aquele meio, sem que haja a exclusão" (Geografia, $8^{\circ}$ período). As questões levantadas por Ísis e Jade indicam que a comunicação entre professor ouvinte e aluno Surdo aproximam o aluno do reconhecimento da sua própria língua e cultura. Além disso, apoiam o processo de inclusão desse aluno, respeitando suas especificidades. Santana e Bergamo (2005) refletem sobre os

\section{Gláuks: Revista de Letras e Artes-jan/jun. 2020 -Vol. 20, $N^{o} 1$}


processos de discriminação, os quais levam à exclusão social e profissional. Os autores afirmam que a diferença nas modalidades linguísticas das línguas orais para as línguas de sinais pode causar discrepância e hierarquizações. A relação entre a língua de sinais e a cultura expressam "o direito de pertença a um mundo particular" (SANTANA; BERGAMO, 2005, p.566).

Lembramos, a partir de Quadros e Paterno (2006, p.23,24), que o Decreto 5.626/2005 vai surgir da política linguística de confirmação do status linguístico e da representatividade da Libras para os Surdos no Brasil. Desse modo, esta ação também irá preparar um terreno fértil para a origem de outras políticas em prol dos Surdos. A inserção da disciplina de Libras nos cursos de formação de professores vem para preparar os futuros docentes para atender às demandas de seus alunos Surdos. Também, os conhecimentos obtidos na disciplina poderão fazer com que futuramente as aulas desses professores sejam preparadas de maneira inclusiva, proporcionando subsídios teóricos para tecer discussões inclusivas no espaço escolar.

Nesse cenário, "a promulgação desse decreto mudou o status da Libras na sociedade brasileira e a implementação da disciplina vem modificando o conjunto de crenças de seus destinatários (alunos de graduação), embora esperássemos um efeito mais abrangente" (SOUSA; AFONSO, 2016, p.53). Assim como menciona Heloise, “após cursá-la aprendi diversos sinais e também sobre a história, conquistas, leis, metodologias de ensino entre outras coisas para a comunidade Surda" (Heloise, $10^{\circ}$ período, Física). Então, consideramos que essa disciplina possibilita a formação de novos agentes de políticas linguísticas apoiando a inserção dos Surdos no contexto educacional brasileiro inclusivo. Profissionais passam a ser inseridos ambiente escolar com um olhar minimamente desconstruído sobre os Surdos, com informações teóricas e práticas que corroboram com a perspectiva inclusiva.

Gláuks: Revista de Letras e Artes-jan/jun. 2020 - Vol. 20, $N^{o} 1$ 
A urgência de uma formação crítica aos licenciandos é apontada por Mastrella (2019). A autora, ao discutir sobre aulas de estágio no ensino de Inglês, discorre que, ao "adentrar a escola para a formação docente crítica e decolonial implica se ver em um novo espaço. Implica abertura de espírito para entendê-lo como um espaço outro, em um momento outro, com pessoas outras" (MASTRELLA, 2019, p.11). Sendo assim, Kauã apresenta a percepção de que finalizou "a disciplina com a consciência de estar apto a lidar com alunos surdos da melhor maneira na vida profissional" (Kauã, Ciências Sociais, $4^{\circ}$ período). Assim como Mastrella aponta, a aproximação dos licenciandos à realidade da educação de Surdos e sua presença no ambiente escolar apoia a construção de uma formação decolonial.

Outro aspecto é o distanciando de ideias equivocadas e/ou crendices sobre esse grupo minoritário. Segundo Campos (2012, p.45), a compreensão da língua de sinais por parte dos professores é fundamental, já que isso pode conduzi-los a organizar sua aula de forma a atender as especificidades dos alunos Surdos presentes em sala. Entretanto, caso os docentes não possuam conhecimento da Libras, sua aula seguirá "normalmente" na língua oral predominante e sem considerar qualquer adaptação ou, até mesmo, a presença do aluno Surdo e o uso de sua língua como principal meio de comunicação.

Luís indica que a disciplina ofereceu suporte para que ele se sentisse mais seguro para atuar com alunos Surdos. A partir do contato com temáticas até então desconhecidas, pouco disseminadas em outras disciplinas durante os cursos de licenciaturas, o discente descreve que provavelmente não teria oportunidade de discutir sobre a Libras e a educação de Surdos fora desse contexto: "Com a disciplina, muito mais do que a língua em si, aprendi um pouco mais do universo dos Surdos e olhar para eles com mais atenção, pensando em estratégias para incluí-las em minhas aulas e vida social" (Luís, Letras, $6^{\circ}$ período). Percebemos nesse caso, vestígios decoloniais já incorporados no perfil de um aluno que até cursar a disciplina

Gláuks: Revista de Letras e Artes-jan/jun. 2020 - Vol. 20, $N^{o} 1$ 
declarou não ter conhecimento sobre a Libras. De acordo com Campos (2012), no contexto de ensino público brasileiro, uma prática frequente é a de ignorar o aluno Surdo em sala de aula, muitas vezes, no que tange a metodologias que partem da utilização da Libras. São atitudes como essa que a autora descreve que provocam defasagem no processo de ensino e aprendizagem do aluno Surdo, produzindo, com isso, práticas excludentes.

As questões de inclusão/exclusão demarcam a influência colonial, desconsiderando a diversidade dos alunos, assim como o distanciamento para atender às especificidades. Tais questões precisam ser superadas urgentemente na escola para que ela adquira carácter inclusivo. Max nos mostra que a disciplina influenciou para uma prática docente a caminho do decolonialismo no ensino:

Eu sabia apenas o alfabeto em libras e muito pouco sobre a educação dos surdos. Após a disciplina, meu vocabulário aumentou e aprendi sobre a importância de incluir o aluno surdo na sua aula e as diversas formas de fazer isso (Max, Educação Física, $6^{\circ}$ período).

Posto isso, ao levar em consideração o contexto histórico da educação de Surdos e o reconhecimento da Libras como um processo de decolonialidade, entendemos que as ações voltadas para mudanças de perspectivas a esse respeito na formação inicial de professores sejam evidenciadas como uma possibilidade de alteração do olhar de forma colonial para os sujeitos Surdos e sua língua

Gláuks: Revista de Letras e Artes-jan/jun. 2020 - Vol. 20, $N^{o} 1$ 


\section{Algumas considerações}

Neste artigo, apresentamos duas discussões teóricas de pano de fundo da temática de formação inicial de professores e as reflexões geradas por meio de uma disciplina de Libras. As transformações citadas acima com relação às noções e práticas dos futuros docentes indicam passos de afastamento da influência colonial no ensino. As políticas linguísticas desenharam aos poucos um novo contexto com relação à vivência dos Surdos em sociedade. Acreditamos que muitas mudanças ocorreram nos espaços escolares após mais de uma década da implementação das disciplinas no ES. Diferentes grupos de licenciandos puderam ter acesso às questões que permeiam o mundo Surdo e suas especificidades educacionais e, consequentemente, desenvolveram transformações mesmo que sutis na comunidade escolar.

Verificamos que mitos e crenças foram desconstruídos, sendo que alguns deles diziam respeito diretamente ao processo de ensino e aprendizagem de uma língua e, outros, referiamse aos mitos em torno da língua e de seus usuários. A habilidade de aprender uma língua involucra-se no âmbito de um debate bastante amplo que já vem sendo realizado na Linguística Aplicada e trouxemos breves apontamentos (BARCELOS, 2004; MASTRELLADE-ANDRADE, 2019). No que se refere às pré-concepções que os licenciandos tinham acerca da Libras e seus usuários, estas demonstram dispositivos de colonização, voltados para o etnocentrismo, mesmo que de forma naturalizada.

A experiência positiva apresentada pelos licenciandos demonstram que a organização do conteúdo programático com respaldado em discussões teóricas direcionam para reflexões decoloniais. Pontuamos que a disciplina tem espaço para discussões que possibilitam a transformação de noções sobre a Libras e a surdez, a compreensão da história, da identidade e

Gláuks: Revista de Letras e Artes-jan/jun. 2020 -Vol. 20, $N^{o} 1$ 
da cultura Surda. Sendo assim, permitiu um olhar crítico frente à língua e seu uso social oralmente normalizado.

Ademais, entrelaçada às considerações sobre inclusão x exclusão, notamos que no momento em que há uma abertura para métodos e estratégias de ensino que favoreçam o processo de ensino e aprendizagem dos Surdos, há a abertura para um processo reflexivo sobre o lugar da língua e dos sujeitos no contexto escolar. Isso dimensiona o viés de ação em torno das políticas linguísticas, que provavelmente a maioria dos discentes não teria acesso sem essa disciplina específica.

Após a realização desse trabalho, identificamos a necessidade de mais pesquisas envolvendo o perfil do docente de línguas em uma perspectiva decolonial que tragam outros temas emergentes, tais como as questões de gênero, raça e classe, envolvendo línguas minoritárias.

\section{Referências bibliográficas}

ALBRES, N. A. História da língua de sinais em Campo Grande - MS. Petrópolis: ARARA AZUL, 2005. $<$ https://www.porsinal.pt/index.php?ps=artigos\&idt=artc\&cat=7\&idart=60>. Acesso em: 22 mar. 2020.

BARCELOS, A. M. F. Crenças sobre aprendizagem de línguas, Lingüistica Aplicada e ensino de línguas. Revista Linguagem \& Ensino, v. 7, n. 1, p. 123-156, 2004. Disponível:<em:http://www.leffa.pro.br/tela4/Textos/Textos/Revista/edicoes/v7n1/ G_Ana_Maria_Barcelos2.pdf $>$.Acesso em 20 abr. 2020.

Gláuks: Revista de Letras e Artes-jan/jun. 2020 - Vol. 20, $N^{o} 1$ 
BRASIL. Lei $n^{\circ}$ 9.394, de 20 de dezembro de 1996. Estabelece as diretrizes e bases da educação nacional. Diário Oficial [da República Federativa do Brasil], Brasília, 225, DF, v. 134, n. 248, 23 dez. 1996. Seção I, p. 27834-27841. Disponível em: $<$ https://www.jusbrasil.com.br/busca?q=Art.+62+da+Lei+de+Diretrizes+e+Bases++Lei+9394\%2F96>. Acesso em: 20 abr. 2020.

Lei 10.436 de 24 de abril de 2002. Dispõe sobre a regulamentação da LIBRAS. Disponível em: <http://www.libras.org.br/leilibras.php>. Acesso em: 29 abr. 2020.

Decreto n. 5.626, de 22 de dezembro de 2005. Regulamenta a Lei no 10.436, de 24 de abril de 2002, que dispõe sobre a Língua Brasileira de Sinais - Libras, e o art. 18 da Lei no 10.098, de 19 de dezembro de 2000. Disponível em: $<$ http://www.planalto.gov.br/ccivil_03/_ato2004-2006/2005/decreto/d5626.htm> Acesso em: 29 abr. 2020.

BRITO, L. F. Por uma gramática de língua de sinais. Rio de Janeiro: Tempo Brasileiro/UFRJ, 1995.

CAMPOS, S. R. O Papel da Língua de Sinais na Constituição do Surdo como Estudante. In: Giroto, C. R. M.; Martins, S. E. O. \& Berberian, A. P. (Org.). Surdez e Educação Inclusiva.Marília.37-54.2012. Disponível em: $<\underline{\text { https://www.marilia.unesp.br/Home/Publicacoes/af- }}$ v7 obraindividual_giroto_martins berberian_2012-pcg.pdf $>$. Acesso em 20 abr. 2020.

DAMÁZIO, M. F. M. O Atendimento Educacional Especializado para a pessoa com surdez. SEESP / SEED / MEC Brasília/DF - 2007.

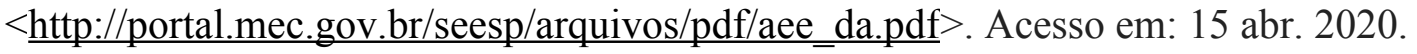

DE AQUINO, S. R. A implantação da LIBRAS nas licenciaturas: desmistificando conceitos. Revista Educação, Artes e Inclusão, v. 13, n. 3, p. 073-098, 2017. Disponível em:

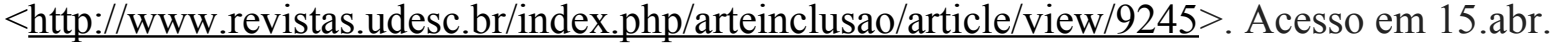
2020 .

DIZEU, L.C. T. B; CAPORALI, S.A. A língua de sinais constituindo o surdo como sujeito. Educação \& Sociedade, v. 26, n. 91, p. 583-597, 2005. Disponível em:

$<$ https://www.scielo.br/pdf/es/v26n91/a14v2691.pdf $>$ Acesso em 15.abr. 2020.

Gláuks: Revista de Letras e Artes-jan/jun. 2020 -Vol. 20, $N^{o} 1$ 
DURANTI, A. The scope of Linguistic Anthropology. In: Linguistic Anthropology. New York, NY: Cambridge University Press, 1997.

FONTE, Z. M. L. F. A educação de surdos e a prática pedagógica dos professores ouvintes: análise a partir do Programa Nacional de Apoio à Educação de Surdos. 2005. Tese de Doutorado. Dissertação de Mestrado. Universidade Federal de Pernambuco. Recife.

GESSER, A. Libras? que língua é essa?: crenças e preconceitos em torno da língua de sinais e da realidade surda. Parábola Ed., 2009.

GIL, A. C. Métodos e técnicas de pesquisa social. 6. ed. Editora Atlas SA, 2008. Disponível em: $<$ https://ayanrafael.files.wordpress.com/2011/08/gil-a-c-mc3a9todos-e-tc3a9cnicas-depesquisa-social.pdf $>$. Acesso em 10 abr. 2020.

GÓES, M.C.R. Linguagem, surdez e educação. 2. ed. Campinas: Autores Associados, 1999.

KOZLOWSKI, Lorena. O modelo bilíngue/bicultural na educação do surdo. Distúrbios da Comunicação, v. 7, n. 2, 1995.

LAPLANTINE, F. Aprender Antropologia. São Paulo: Ed. Brasiliense, 2003.

LEMOS, A. M; CHAVES, E. P. A disciplina de Libras no ensino superior: da proposição à prática de ensino como segunda língua. XVI ENDIPE-Encontro Nacional de Didática e Práticas de Ensino-Campinas: UNICAMP, 2012. Disponível em:

$<$ http://livrozilla.com/doc/1438363/a-disciplina-de-libras-no-ensino-superior--da $>$.Acesso em 13 mar. 2020.

MASTRELLA. A. M. R. Abandonamos a sala da universidade: uma opção decolonial no estágio de inglês e na formação docente crítica. Revista Brasileira de Linguística Aplicada, n. AHEAD, 2019. Disponível em: http://www.scielo.br/scielo.php?

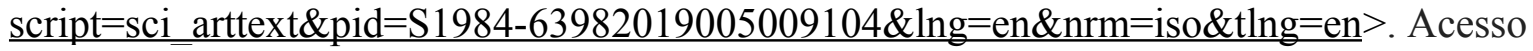
em 15 abr.2020.

MARTINS, V. R. O. Análise das vantagens e desvantagens da Libras como disciplina curricular no ensino superior. Cadernos do CEOM- Ano 21, n. 28 - Memória, História e Educação -Chapecó: Argos, 2008. Disponível:

Gláuks: Revista de Letras e Artes-jan/jun. 2020 - Vol. 20, $N^{o} 1$ 
$<$ http://bell.unochapeco.edu.br/revistas/index.php/rcc/article/view/161>. Acesso em 15 abr. 2020 .

MEGALE, A. H. Educação bilíngue de línguas de prestígio no Brasil: uma análise dos documentos oficiais. The ESPecialist, v. 39, n. 2, 2018. Disponível em:

,https://revistas.pucsp.br/esp/article/view/38653>. Acesso em 15 abr. 2020.

MIGNOLO, W. Educación y decolonialidad: aprender a desaprender para poder reaprender. [Entrevista cedida a] Facundo Giuliano e Daniel Berisso. Revista del IICE, Buenos Aires, n. 35, p. 61-71, 2014. Disponível em:

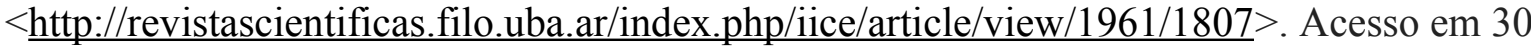
mar. 2020.

MIGNOLO, W. D. Colonialidade: o lado mais escuro da modernidade. Revista Brasileira de Ciências Sociais, v. 32, n. 94, 2017. Disponível em:

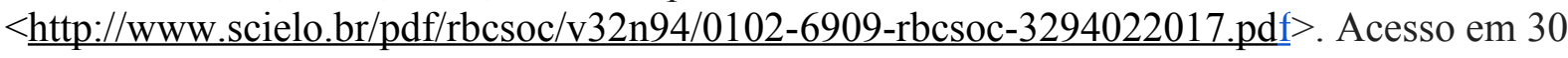
mar. 2020.

O desafio do conhecimento: pesquisa qualitativa em saúde. 5. ed. São Paulo:

Hucitec-Abrasco, 1998.

MINAYO, M. C. S. et al. Pesquisa social: teoria, metodologia e criatividade. Petrópolis (RJ): Vozes, 2012.

NORA, A. B. Um histórico das políticas linguísticas para surdos sinalizantes: da lei de libras ao movimento em prol da escola bilíngue.V.6, Edição número 25, Abril/Setembro. 2017, p.1-19.Disponível em:

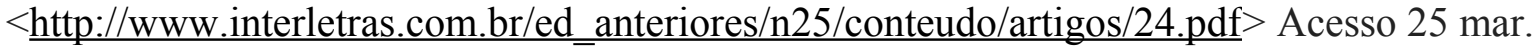
2020.

PADDEN, C; HUMPHRIES, T. 2006. Inside Deaf Culture. Cambridge, Massachusetts: Harvard University Press.

PARDO, F. S. Decolonialidade e ensino de línguas: perspectivas e desafios para a construção do conhecimento corporificado. Revista Letras Raras. Campina Grande, v. 8, n. 3,

Gláuks: Revista de Letras e Artes-jan/jun. 2020 - Vol. 20, $N^{o} 1$ 
p. Port. 200-221 / Eng. 198-218, set. 2019. ISSN 2317-2347. Disponível em:

$<$ http://revistas.ufcg.edu.br/ch/index.php/RLR/article/view/1422>. Acesso em 04. abr .2020.

SCHUBERT, S. E. M; PEREIRA, M. F. R. Limites e possibilidades de formação de professores para a educação bilíngue de surdos: superação do colonialismo. In: Avaliação, políticas e expansão da educação brasileira.Ponta Grossa. 2019. Atena Editora,v.12.p. 388-

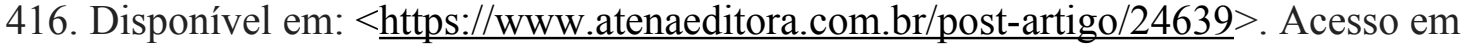
05.abr. 2020.

VIEIRA, C. R; MOLINA, K. S. M. Prática pedagógica na educação de surdos: o entrelaçamento das abordagens no contexto escolar. Educação e Pesquisa, v. 44, 2018. Disponível em: $<$ http://www.scielo.br/scielo.php?pid=S151797022018000100503\&script $=$ sci arttext $>$. Acesso em 30 mar. 2020.

QUADROS, R. M.; PATERNO, U. Políticas linguísticas: o impacto do decreto 5626 para os surdos brasileiros. Espaço (INES), v. 1, p. 19-25, 2006. Disponível em: < $\underline{\text { https://cultura- }}$ sorda.org/wp-content/uploads/2015/03/INES_Revista_Espaco_2006.pdf $>$ Acesso em 28 abr. 2020.

QUADROS, R. M; KARNOPP, L. B. Língua brasileira de sinais: estudos linguísticos. Porto Alegre: Artmed, 2004.

RAJAGOPALAN, K. Politica linguística: do que é que se trata, afinal. Política e Políticas Linguísticas. Campinas: Pontes Editores, 2013.

SEVERO, C. G. Política (s) linguística (s) e questões de poder. Alfa: Revista de Linguística (São José do Rio Preto), v. 57, n. 2, p. 451-473, 2013. Disponível em:

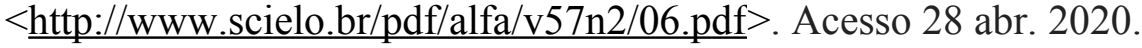

SILVA, C. M; SILVA D. S; MONTEIRO, R.; SILVA, D. N. H. Inclusão Escolar: Concepções dos Profissionais da Escola sobre o Surdo e a Surdez. Psicologia: Ciência e Profissão jul./set. 2018 v. 38 n³, 465-479. Disponível em:

$<$ http://www.scielo.br/pdf/pcp/v38n3/1982-3703-pcp-38-3-0465.pdf $>$. Acesso 28 abr. 2020.

SOUSA, S. C. T; AFONSO, L. A. Políticas linguísticas sobre a Libras: as crenças dos estudantes de letras. 2016. Disponível em:

Gláuks: Revista de Letras e Artes-jan/jun. 2020 - Vol. 20, $N^{o} 1$ 
$<$ https://pdfs.semanticscholar.org/f553/f359e72c41b8a0d318262ed2954a48959263.pdf > Aces so em 09 abr.2020.

SOUSA, S.C. T; SOARES, M. E. Um estudo sobre as políticas linguísticas no Brasil. 2014.

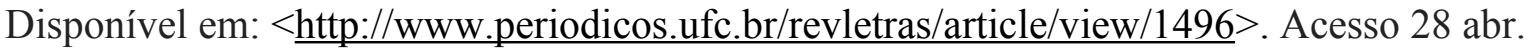
2020.

XAVIER, A. N. De que forma a disciplina "libras" pode contribuir com a formação de professores para a educação inclusiva?. Revista Sinalizar, v. 3, n. 2, p. 3-24, 2018.Disponível

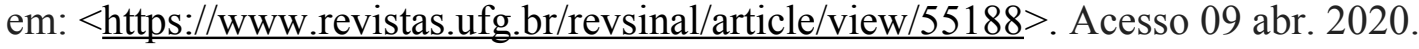

\begin{abstract}
This work aims to reflect about the implications of Libras' course in teacher training according undergraduate students perceptions from different areas of knowledge. In an analysis built in the field of Applied Linguistics and crossed by the discussion that involves linguistic politics and the notions of decoloniality we discuss the complexity to develop a course from multiple perspectives. We pointed out some aspects as a standardization, recognition, linguistic status and equal rights of minority groups to use their first language. The methodology is described from this context to develop the research. Then, we discuss the role of Libras' course to build critical knowledge in terms of contents and objectives, which involve the understanding of Libras as first and as a second language, the interpretation of aspects related to teacher formation focused on diversity and inclusion and the relationship between teaching a language and pedagogical practices. Finally, we conclude that the course has a critical reflexive role training the future teachers, involving the point of view to look at the language and its social use.
\end{abstract}

Keywords: Libras' course; teacher formation; decoloniality; linguistic politics; teaching language.

Gláuks: Revista de Letras e Artes-jan/jun. 2020 -Vol. 20, $N^{o} 1$ 